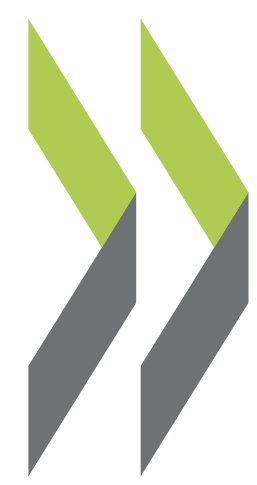

CELE Exchange, Centre for Effective Learning Environments 2010/02

\title{
Flexible and Alternative Approaches to Providing School Infrastructure in Alberta, Canada
}

\section{Allison Matichuk}

https://dx.doi.org/10.1787/5kmh36j9vwmw-en 


\section{Flexible and alternative approaches to providing school infrastructure in Alberta, Canada}

By Allison Matichuk, Alberta Education, Canada

Like many other jurisdictions, the western Canadian province of Alberta is seeking cost-effective and creative ways of providing school infrastructure that meets the needs of $21^{\text {st }}$ century learning. Solutions are being found through the use of alternative financing and procurement arrangements and through innovative approaches to creating flexible school facilities.

\section{Province of Alberta}

Population: 3.6 million

Size: 662000 square kilometers

Number of schools (public and private): 2091

Number of students: 596113

\section{ALTERNATIVE FINANCING AND PROCUREMENT}

\section{"Alberta Schools Alternative Procurement" initiative}

In 2007, Alberta announced the first phase of the Alberta Schools Alternative Procurement (ASAP) initiative: 18 new schools, providing 12000 new spaces. ASAP Phase 1 is the largest kindergartento-Grade 9 schools project in Canada. It builds on the experiences of similar large-scale investment operations seen recently in various countries and adapts the Design-Build-Finance-Maintain concept to meet Alberta's educational infrastructure needs.

This project involves a public-private partnership (P3) between the Government of Alberta and a private consortium selected through an open competition. For ASAP 1, the contract was awarded to BBPP Alberta Schools Limited. Under Alberta's P3 arrangement, the schools will be owned and operated by the respective four project school boards in Calgary and Edmonton. Once the schools are completed in June 2010, the province will advance CAD 125 million of the overall CAD 634 million contract to the consortium and will at that time begin capital and maintenance payments for a 30-year term. The maintenance agreement requires the contractor to provide major maintenance for repairs such as boilers and roof replacements. Prior to the end of the 30-year period there is a hold back provision to ensure the schools are in good condition before the responsibility for maintenance is transferred to 
the school boards. The contractor is required to meet pre-defined service and building performance standards, with provision for the province to hold back maintenance payments in the event of nonperformance.

Numerous advantages are being realised through this type of alternative procurement. This P3 approach constructs the schools within three years, while conventional/traditional build models can take as long as five years. Constructing several schools simultaneously and with similar designs also reduces initial construction costs by taking advantage of economies of scale. The long-term maintenance agreement with a single contractor allows for similar economies and provides the added benefit of fixed and foreseeable maintenance costs over the next three decades. It also provides an additional incentive for the contractor to build a high-quality facility.

All 18 of the ASAP Phase 1 schools are ahead of schedule for their anticipated opening date of September 2010. ASAP Phase 2, announced in January 2008, will see 10 more schools constructed under a P3 model and four high schools built under a single Design-Build contract. These 14 schools will be completed in two stages in 2012 and 2013.

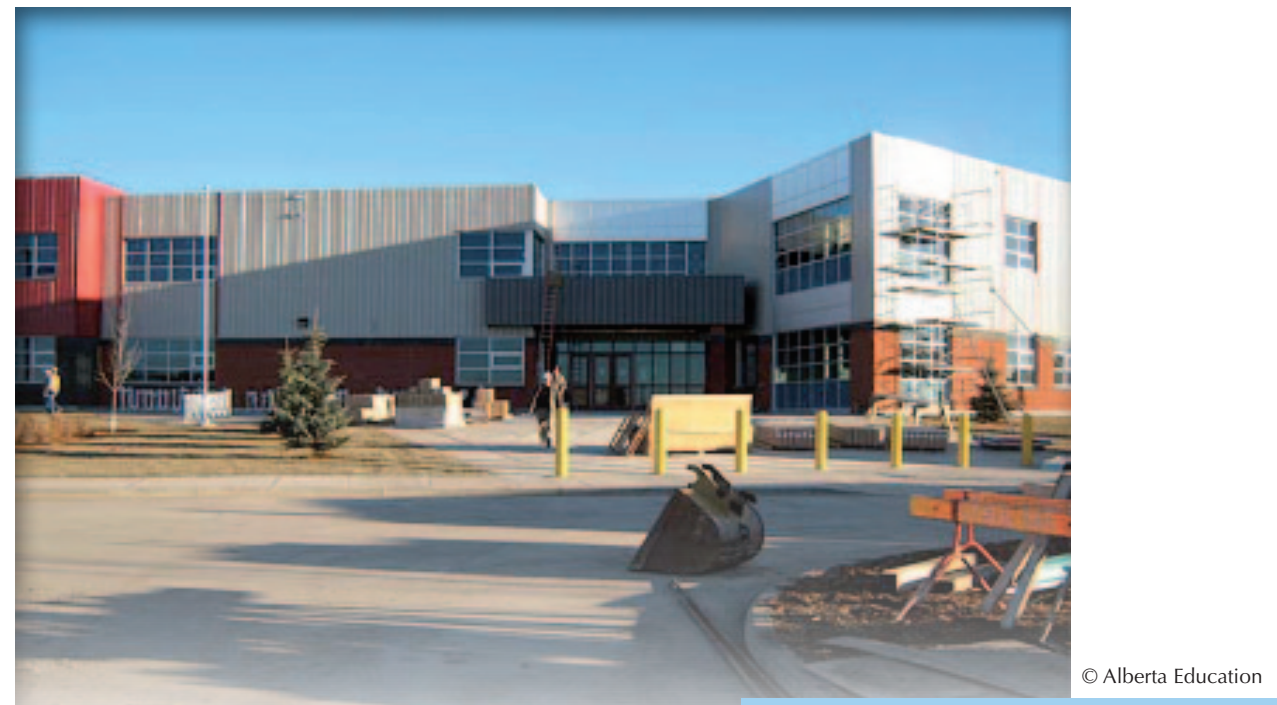

An ASAP school under construction in Edmonton, Alberta

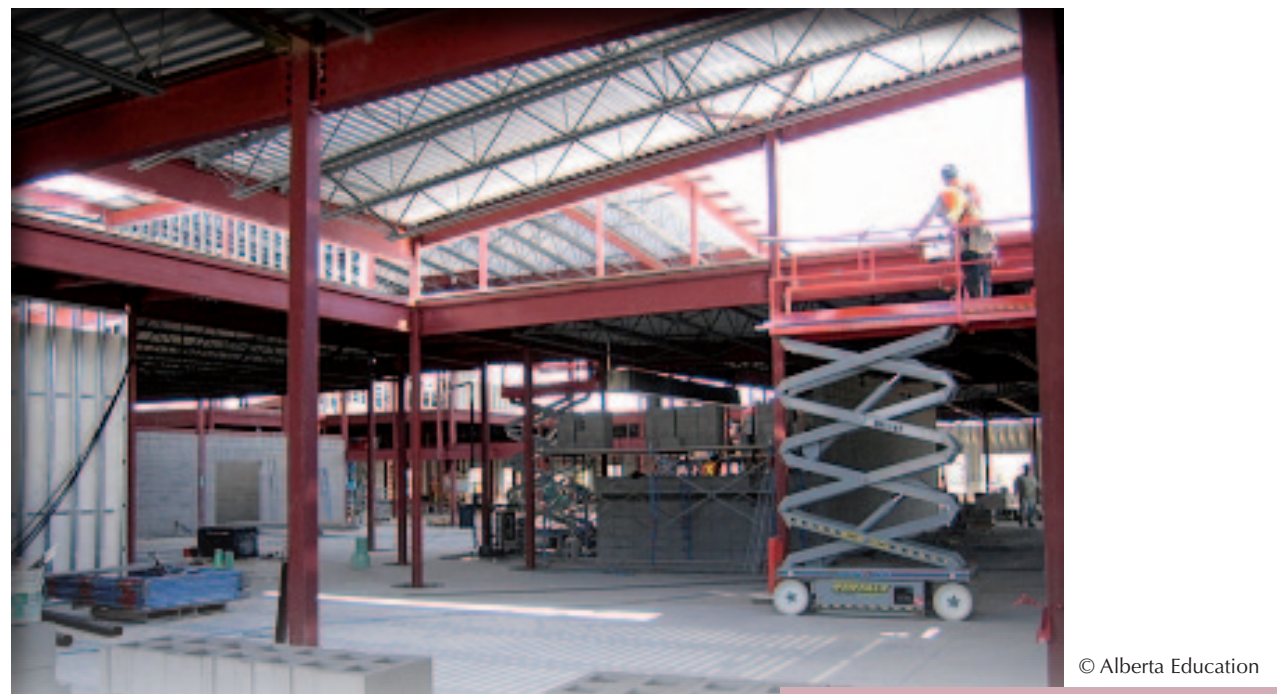

An ASAP school under construction in Calgary, Alberta 


\section{Other partnerships}

In addition to the ASAP initiative, the Alberta government and local school boards have been exploring other forms of partnerships for the financing and construction of new schools. There are now several communities where the construction and financing of a new school building or the renovation of an existing building is - or has been - jointly undertaken by the provincial government and the municipality. The resulting facility serves the needs of local students but also those of the broader public through the inclusion of other community resources incorporated or attached to the school.

Recent examples of joint projects include the Cold Lake Energy Centre which used privately donated land to build a facility with amenities shared between a municipal recreation centre, child care centre, senior high school and a post-secondary institution. The Olds Community Learning Campus is another innovative project integrating a senior high school and a college into multiple new facilities built on the college campus, including an e-learning centre, a recreation facility and a fine arts and multimedia centre. In both of these examples, the facilities have become focal points for their respective communities and are providing opportunities for improved student transitions from secondary to post secondary education.

\section{FLEXIBLE FACILITIES}

Alberta has begun to implement several innovative design features that allow its school buildings the flexibility to adapt to fluctuating enrolment levels and educational needs.

\section{Core schools and modular classrooms}

The ASAP projects involve the use of a set of standard core school designs that can be adapted to meet educational needs at the local level. Seven core designs have been developed by government for specific population sizes and grade configurations. Each design incorporates a permanent core with modular classrooms that can be added or removed as student enrolment changes. School jurisdictions have the flexibility to tailor the components within the core structure to address their unique requirements or particular education needs. Using consistent building designs and standardized modular classrooms across the province provides the flexibility to relocate modular classrooms from one school to another with a minimum of disruption and expense. Environmental impact is lessened by relocating modular classrooms to address enrolment fluctuations rather than constructing and/or demolishing classroom space.

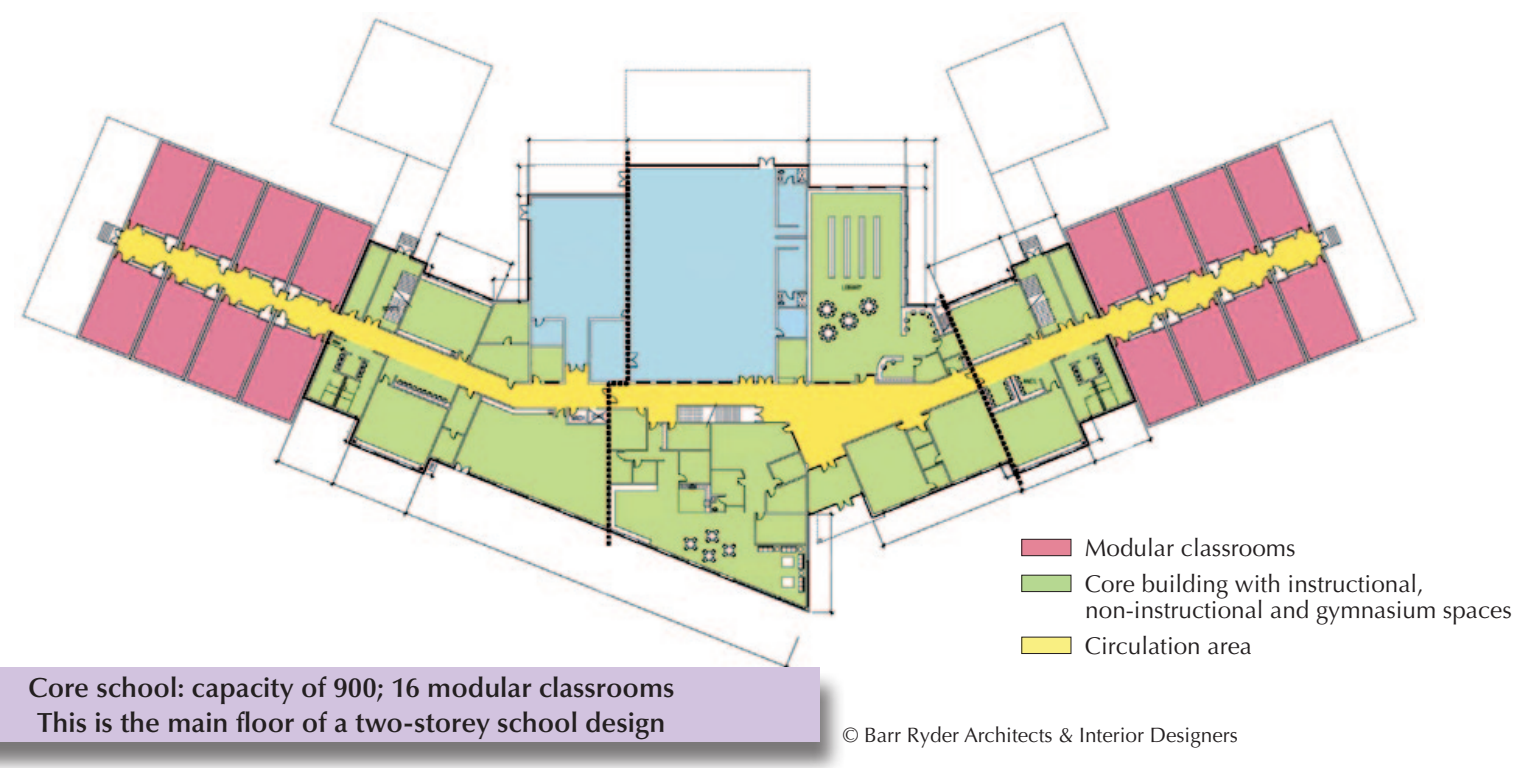


Portable classrooms of the past were usually considered temporary measures to address short-term needs, and the quality of their construction and design was commensurate with that expectation. Today's modular classrooms are comfortable, efficient and highly effective learning environments. The interiors look like permanent classrooms, thanks to the use of painted drywall, drop ceilings and large windows. The units are durable and are designed to allow multiple moves. Alberta's new school designs incorporate modular classrooms as an intentional and integral part of the building's functionality.

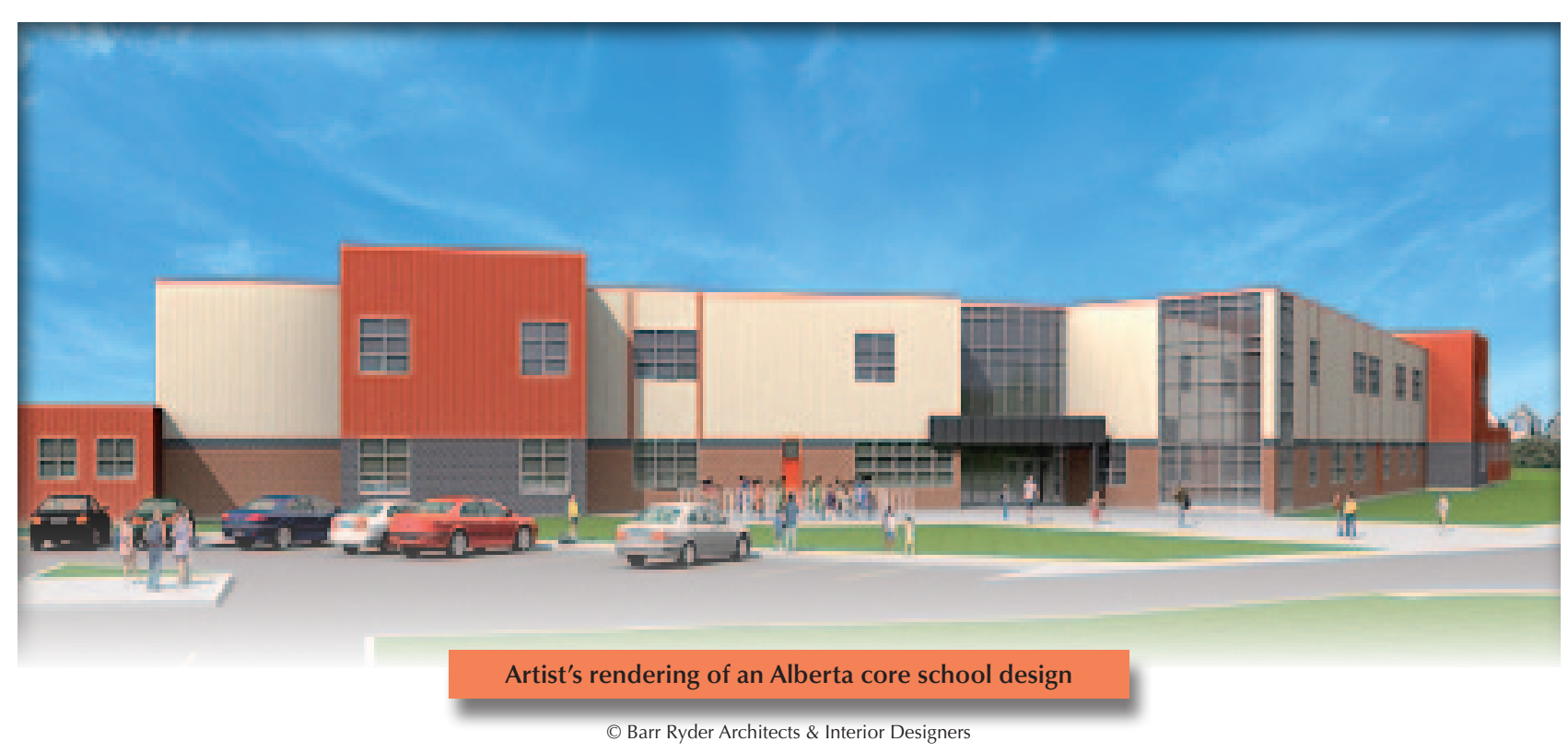

The core schools and modular classrooms of the ASAP project all meet LEED (Leadership in Energy and Environmental Design) silver rating requirements, making them more energy efficient than conventional buildings and providing healthier environments through improved air quality and use of natural light.

\section{Career and technology studies facilities}

An extension of the modular classroom concept is the mobile Career and Technology Studies (CTS) unit. CTS is a programme that helps Alberta high school students explore and develop skills that are directly applicable to specific career paths in areas such as trades, technology, health and sustainable resources. The "hands-on" nature of the CTS courses requires access to specialised equipment in appropriate facilities.

Mobile CTS units are providing a cost-effective solution for some Alberta school jurisdictions. These specially constructed and equipped mobile trailers can be moved from one school to another so that two or more schools can each have access to the lab for a portion of the school year. This is especially effective in rural areas where there is considerable distance between high schools and where the number of students is relatively small. There are currently six mobile CTS units in use in Alberta school jurisdictions. 

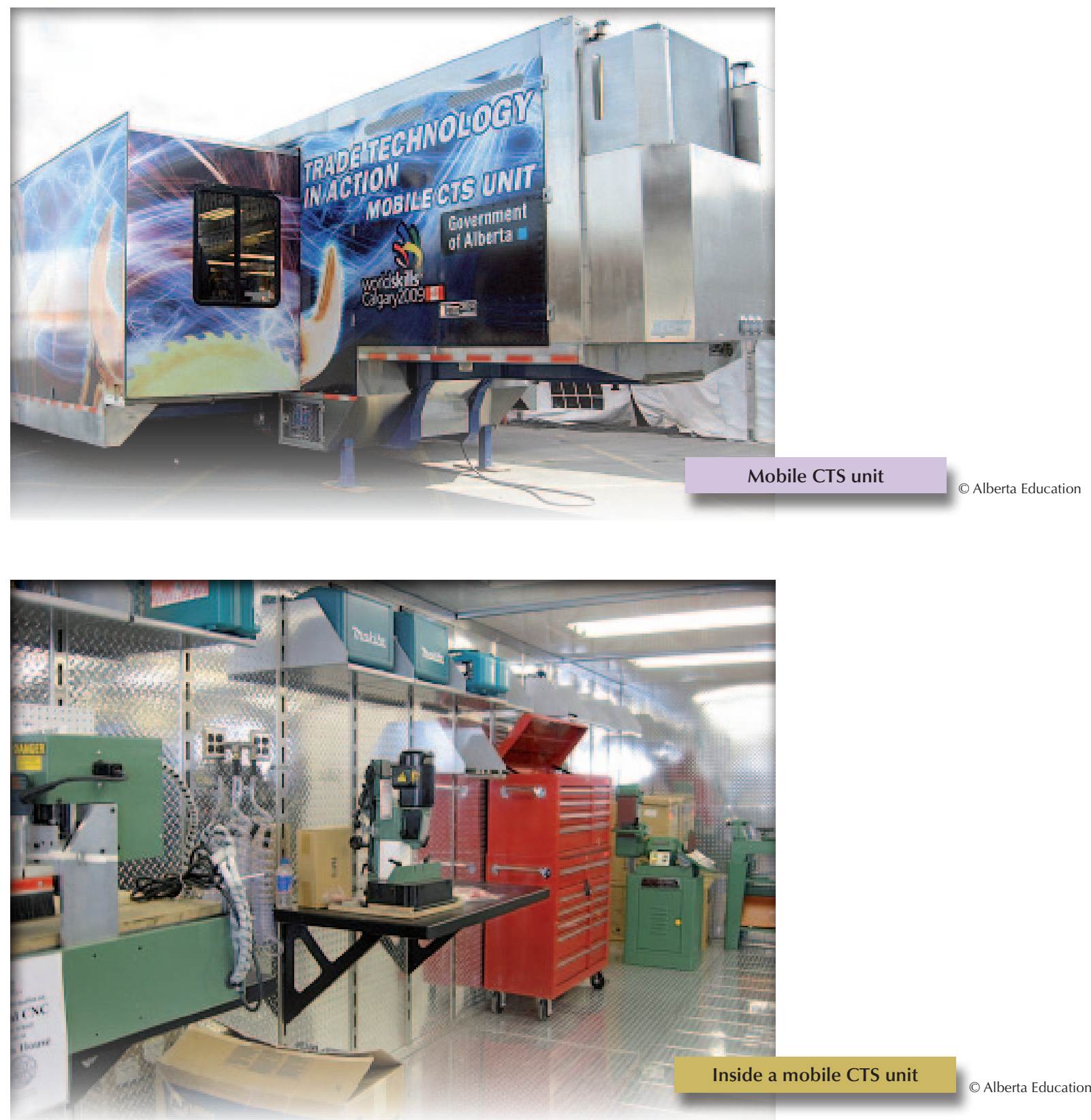

\section{Technology}

New schools in Alberta are also being built and equipped to accommodate the increasing importance of technology in the delivery of education. Features that are becoming standard include greater access to power supplies, walls that are prepared for electronic whiteboard installation and provisions for wireless network transmitters. The specifications for two of Alberta's standard core school designs include computer ports in all of the instructional spaces and teacher stations.

Several years ago, the Alberta government built a broadband fibre optic network to connect public institutions across the province - schools, hospitals, colleges, universities, libraries and municipal offices. This "SuperNet" provides high-speed Internet access, video conferencing and other services to Alberta schools in even the remotest areas of the province. A southern Alberta school jurisdiction 
recently used a satellite hook-up to allow students to speak in real-time with astronauts aboard the International Space Station. SuperNet at the host school provided the broadband capacity needed to stream the event live to schools around the province and the world, allowing more students to share in this historic event.

In addition to providing access to learning opportunities, the broadband capability provided by SuperNet is being used by some schools to remotely operate their climate control systems and to install Voice Over Internet Protocol phones to reduce telecommunications costs.

\section{CONCLUSION}

Alberta is using public-private partnerships as one way to quickly and cost-effectively build schools in areas of the province that are experiencing enrolment pressures. Through the use of core school designs, modular classrooms, Career and Technology Studies units and technology-ready school buildings, the province is ensuring that its schools are flexible enough to adapt to changing demographics and to the evolving needs of learners in Alberta.

For more information, contact:

Laura Cameron

Executive Director, Capital Planning

Alberta Education

$2^{\text {nd }}$ floor, 44 Capital Boulevard

10044108 Street NW

Edmonton, Alberta

Canada T5J 5E6

E-mail: laura.cameron@gov.ab.ca

www.education.alberta.ca 


\section{ORGANISATION FOR ECONOMIC CO-OPERATION AND DEVELOPMENT}

The OECD is a unique forum where the governments of 30 democracies work together to address the economic, social and environmental challenges of globalisation. The OECD is also at the forefront of efforts to understand and to help governments respond to new developments and concerns, such as corporate governance, the information economy and the challenges of an ageing population. The Organisation provides a setting where governments can compare policy experiences, seek answers to common problems, identify good practice and work to co-ordinate domestic and international policies.

The OECD member countries are: Australia, Austria, Belgium, Canada, the Czech Republic, Denmark, Finland, France, Germany, Greece, Hungary, Iceland, Ireland, Italy, Japan, Korea, Luxembourg, Mexico, the Netherlands, New Zealand, Norway, Poland, Portugal, the Slovak Republic, Spain, Sweden, Switzerland, Turkey, the United Kingdom and the United States. The Commission of the European Communities takes part in the work of the OECD.

OECD Publishing disseminates widely the results of the Organisation's statistics gathering and research on economic, social and environmental issues, as well as the conventions, guidelines and standards agreed by its members.

This work is published under the responsibility of the Secretary General of the OECD. The opinions expressed and arguments employed herein do not necessarily reflect the official views of the Organisation or of the governments of its member countries.

You can copy, download or print OECD content for your own use, and you can include excerpts from OECD publications, databases and multimedia products in your own documents, presentations, blogs, websites and teaching materials, provided that suitable acknowledgment of OECD as source and copyright owner is given. All requests for public or commercial use and translation rights should be submitted to rights@oecd.org. Requests for permission to photocopy portions of this material requests for public or commercial use and translation rights should be submitted to rights@oecd.org. Requests for permission to photocopy portions of this material
for public or commercial use shall be addressed directly to the Copyright Clearance Center (CCC) at info@copyright.com or the Centre français d'exploitation du droit de copie (CFC) contact@cfcopies.com. 